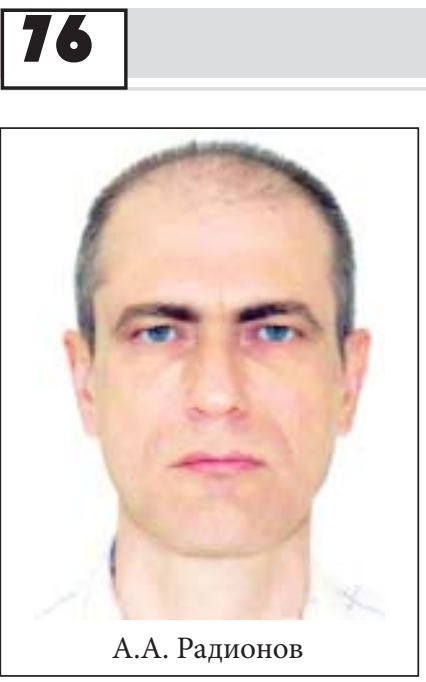

\title{
О ВОЗМОЖНОМ МЕХАНИЗМЕ ВОЗНИКНОВЕНИЯ ГЛУБОКОВОДНЫХ ОКЕАНИЧЕСКИХ ЖЕЛОБОВ
}

\section{А.А. Радионов"}

\begin{abstract}
Аннотация. Предлагается простая теоретическая модель физических процессов, приводящих к возникновению глубоководных океанических желобов. Обсуждаются физические причины существования протяженных прогибов в океанической коре. В рамках рассматриваемых физических механизмов предполагается существование мантийного струйного течения, движущегося под океанической впадиной, вдоль ее направления, сердцевина которого расположена на глубинах порядка десятка километров ниже дна океана. Давление над движущейся мантийной струей меньше, чем давление над окружающей неподвижной мантией. Эта разница давления может приводить к появлению прогиба дна океана и являться вертикально действующей силой, приводящей к возникновению океанических желобов. Обсуждаются возможные причины, приводящие к возникновению струйных мантийных течений.
\end{abstract}

Ключевые слова: математическая модель, океанический желоб, струйное течение.

\section{ВВЕДЕНИЕ}

В мировом океане наблюдаются прогибы океанического дна, располагающиеся вдоль островных дуг или окраин континентальных горноскладчатых сооружений, протяженностью до нескольких тысяч километров, сравнительно небольшой ширины - от 100 до 200 км, имеющие зачастую асимметричные склоны (со стороны островной дуги углы падения 10-30 ${ }^{\circ}$, со стороны океана $-5-8^{\circ}$ ) и глубиной до 7-9 км (максимальная измеренная глубина равна 11022 м в Марианском желобе). Такие прогибы называются глубоководными желобами, и в мировом океане таких структур множество, например, желоба Алеутский, Камчатско-Курильский, Японский, Идзу-Бонинский, Волкано, Марианский, Тонга, Кермадек, Зондский, Южно-Сандвичев, Пуэрто-Рико Центральноамериканский, Перуанский, Чилийский.

Современные представления о механизме происхождения глубоководных океанических желобов связаны с представлениями о тектонике плит [1, 2], согласно которой указанные желоба - одна из проявленных фрорм взаимодействия горизонтально движущихся океанических и континентальных плит. Довольно тонкая океаническая плита медленно, с характерными скоростями порядка 1-5 см в год, раздвигается вблизи рифтовых вулканических хребтов (их называют зонами спрединга), равномерно в разные стороны. Такое поведение океанической плиты, несомненно, вызвано действием некоторых сил. Под силой далее будет пониматься определенная причина появления движения или нарушения изостазии.

Считается, что плиты в движение приводят силы трения, которые приложены к нижней части океанической плиты в горизонтальном направлении и которые возникают вследствие вовлечения плиты в движение системой сложных конвективных ячеек в мантии. Движение мантии в конвективных ячейках развивается во всей верхней мантии на сотни километров в глубину, имеет многоуровневую и многоячеистую организацию. Под зонами спредин- га наблюдается восходящее движение мантийных конвективных ячеек, взаимодействие с которым приводит к отталкиванию литосферных плит от осей срединных хребтов.

Действительно, сколь бы большими и сложно организованными не являлись мантийные конвективные ячейки, на некотором расстоянии друг от друга области восходящего движения горячей мантии сменяются областями погружения сравнительно более холодной мантии. Это нисходящее движение может приводить к столкновению расположенных над ним плит и частично увлекать океаническую плиту в нисходящее движение. Места, в которых океаническая плита погружается в глубокие мантийные слои, называются зонами субдукции. Изученные детали процессов погружения океанической плиты на конкретных примерах рассматриваются в множестве работ, в частности $[1,2]$.

Под действием указанных сил океаническая плита (толщиной $\approx 10 \div 15$ км) «подныривает» под значительно более мощную (толщиной до 70 км) континентальную плиту и далее погружается в глубокие слои мантии на глубины около 700 км. По другим данным, в процессе погружения может участвовать и континентальная кора. У приведенных здесь фактов есть экспериментально найденные обоснования, так же как и экспериментально найденные несоответствия, которые обсуждаются в книге [3]. Вот цитата из этой книги: «Сейчас накоплено огромное количество сейсмических измерений, свидетельствующих, что в зонах опускания дна океанов фриксируется утоньшение коры снизу - при океанизации подошва коры (граница Мохоровичича) смещается вверх. Сложность проблемы океанизации континентальной коры заключается в том, что нужно объяснить: в силу каких причин происходит направленное вверх уплотнение низов этой коры до состояния плотности мантии? Ведь такой процесс действует против сил изостазии!»

При осмыслении этих геодинамических процессов возникает множество вопросов, одним из кото- 
рых является неустановленная причина, по которой образованная в результате выплавки более легкая, чем нижерасположенное мантийное вещество, океаническая плита погружается в более тяжелую мантию. Почему океаническая плита при столкновении с континентальной плитой не поднимается вверх, как это происходит при столкновении ледяных полей, когда образуются ледяные торосы? Это позволяет предполагать, что вблизи зон субдукции приложенные к океанической плите силы могут не ограничиваться только силами трения, связанными с течениями мантийного вещества глубоких конвективных ячеек. Вероятно, имеются еще какие-то физические процессы, определяющие эволюцию зон субдукции.

В настоящей работе предпринимается попытка построения непротиворечивого фризического объяснения, основанная на представлениях механики жидкости. Объяснение механизмов формирования океанических желобов нужны для общего понимания возможных причин возникновения деформаций земной поверхности вблизи зон субдукции.

Далее развиваются теоретические представления о произвольной океанической впадине, которая может возникать по той причине, что в глубоких слоях мантии сформировалось мощное струйное течение мантийного вещества. Струйные течения не связаны прямо с очень медленными конвективными мантийными течениями и представляют собой значительно более быстрый поток мантийного вещества.

Под струйным течением будем понимать поток вещества, заключенный внутри некоторого интервала глубин, имеющий значительные скорости вдоль оси потока и ограниченное поперечное сечение (эллиптическое или круглое), существенно меньшее, чем длина этой струи. Скорость течения вещества вдоль струи максимальна на оси и убывает от оси к периферии. Для примера можно представить течение жидкости в трубе - в струйном течении такое же распределение скорости, только отсутствуют твердые стенки трубы. Приблизительную оценку диаметра струи можно получить по ширине океанического желоба.

\section{МАТЕМАТИЧЕСКАЯ МОДЕЛЬ}

Как для протекающих с скоростями звука сейсмических процессов, так и для значительно более медленных процессов, происходящих в коре, составляющее литосферу Земли вещество можно описать в рамках подхода Максвелла [4]. Имеется целый класс моделей вещества, среди которых простейшей является модель тела Максвелла. В рамках этого подхода мантийному веществу приписываются свойства как твердого тела, так и свойства жидкости: деформация $\varepsilon$ вещества под действием внешней силы (описываемой напряжением $\sigma)$ состоит из суммы упругих дефоомаций и вязкого течения, соответствующее реологическое уравнение есть

$$
\frac{d \varepsilon}{d t}=\frac{1}{E} \frac{d \sigma}{d t}+\frac{\sigma}{\mu},
$$

где $E$ - модуль упругости твердого тела, $\mu$ - вязкость жидкости, $t-$ время. Соотношение $t=\mu / E$ является характеристикой рассматриваемого вещества и называется временем релаксации. Далее для простоты положим величины $E$ и $\mu$ постоянными и несущественно меняющимися на глубинах порядка 10 км ниже дна океана. На возможность использования этой модели указывают результаты лабораторных исследований $[5,6]$, такое представление о мантийном веществе использовалось и в исследованиях Магницкого [7]. Известно, что вещество, описываемое моделью Максвелла, реагирует на силу, действующую период времени, длительностью меньше времени релаксации, как твердое тело, а на силу, действующую дольше времени релаксации, - как жидкость. Иначе говоря, в максвелловской реологической модели вещества быстрые процессы смещения (и трещинообразования) будут возмущать волны такие же, как и в твердом теле, а медленные процессы деформирования будут проявляться в течении вещества как жидкости. Еще одна важная особенность тел с реологией Максвелла - это существенная зависимость реологии от температуры: с увеличением температуры уменьшается время релаксации, и свойства жидкости проявляются в большей мере. К аналогичному эффекту приводит и растворение в магматических расплавах воды и других летучих компонентов.

Далее не будем принимать во внимание сколько-нибудь быстрые воздействия, например сейсмические, которые действуют непродолжительное время, гораздо меньшее времени релаксации мантийного вещества. Будем иметь в виду лишь силы, время действия которых превышает время релаксации вещества мантии. Такое ограничение не дает возможности рассматривать поперечные сейсмические волны, продольные волны в такой модели описываются. На вещество мантии действует несколько таких сил, и их влияние, приводящее в движение вещество в мантийном струйном течении, будет обсуждаться в заключении. Забегая вперед, в целом, это те же самые силы, которые приводят к возникновению высотных струйных течений в атмосфрере.

В рамках простой модели ограничимся идеализированным представлением о мантийном веществе и о рассматриваемом струйном течении. Например, плотность вещества океанической плиты меняется в зависимости от давления и температуры, что, несомненно, сказывается уже на глубинах порядка 10 км ниже дна океана, однако учет этих зависимостей выходит за рамки математической модели.

Основное количество известных зон субдукции расположено на дне океана, и они представляют собой океанические глубоководные желоба. Положим, что под поверхностью литосферы, на некоторой глубине, расположен струйный поток мантийного вещества. Примем для простоты, что струйный поток можно считать неограниченным вдоль направления его течения, радиус поперечного сечения этого потока составляет 10-200 километров. Примем, что на оси внутри сечения струи 
достигается максимальная скорость течения $v_{\max }$

Если внутри жидкости под ее поверхностью (и вдоль этой поверхности) имеется струйное течение, то форма поверхности жидкости должна измениться на ней появится прогиб, отслеживающий направление и ширину струи, глубина которого будет зависеть от скорости течения жидкости в струе. Чем ближе к поверхности струя, тем больше глубина прогиба на поверхности, которая будет зависеть от скорости течения жидкости в струе (в рамках упрощенного рассмотрения).

Одним из наиболее общих законов, применяемых для понимания фризической картины того или иного процесса, является закон сохранения энергии. Для струйных течений прямым следствием закона сохранения энергии является уравнение Бернулли [8], которое гласит, что давление вблизи струйного течения будет тем меньше, чем больше значение скорости течения в струе. Введем обозначения: $z$ - вертикальная координата с положительным направлением вверх, $h$ - глубина океанической впадины, $p$ - давление, $\rho \approx 2700 \mathrm{\kappa г} / \mathrm{M}^{3}$ - плотность мантийного вещества, $v$ - скорость течения мантийного вещества, $g=9.8$ $\mathrm{m} / \mathrm{c}^{2}$ - ускорение свободного падения, принимаемое константой, плотность воды в океане $\rho_{w} \approx 1000$

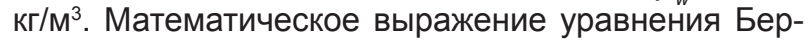
нулли запишем в виде:

$$
\frac{p}{\rho}+g z+\frac{v^{2}}{2}=\text { Const } \text {. }
$$

Константа в правой части постоянна вдоль линии течения в струе, а левая часть не меняется вдоль такой линии. Чтобы применить уравнение Бернулли, рассмотрим ситуацию, при которой струйное течение собирается в узкое поперечное сечение под желобом из очень широкого поперечного сечения вне желоба (которое соответствует удаленным участкам литосферы). В этой ситуации положим, что глубина, на которой располагается струйное течение, не меняется на всех участках, где меняется его поперечное сечение.

Примем поверхность дна океана плоской и будем отсчитывать глубины от поверхности дна океана. Различия между весом вещества над дном внутри впадины и на большом удалении от впадины обусловлены различиями плотностей воды океана и вещества океанической плиты. Весом атмосферы и слоев воды, расположенных выше ровных участков дна, можно пренебречь, поскольку они одинаковы над всеми участками океана. Сделанное предположение схематично иллюстрирует рис. 1.

В ситуации, когда во времени мантийная струя практически не меняет направления и величины скорости своего течения, можно положить константу в правой части записанного уравнения оди-

наковой как для литосферы, удаленной от зоны субдукции, так и для литосферы непосредственно над этой зоной. Запишем уравнение Бернулли для участков струи, расположенных непосредственно под глубоководным желобом:

$$
p_{1}+\rho \frac{v^{2}}{2}=p_{2} .
$$

Здесь обозначено $p_{1}$ - давление непосредственно в самом низком месте впадины, $p_{2}$ - давление на значительном расстоянии от зоны субдукции.

В рамках сделанных предположений можно грубо оценить величину максимальной скорости движения жидкости в струйном течении, поскольку разница давлений $p_{2}-p_{1}$ определяется отличиями веса вещества литосферы и воды:

$$
p_{2}-p_{1}=\left(\rho-\rho_{w}\right) g h,
$$

с учетом этого запишем оценку для скорости:

$$
v_{\text {max }}=\sqrt{\frac{\rho-\rho_{w}}{\rho} 2 g h} .
$$

Используем имеющиеся данные о глубинах океанических желобов и значения плотности мантийного вещества на глубинах, соответствующих струйному течению, чтобы получить диапазон оценок скорости течения в мантийной струе: $v_{\max } \approx$ $140 \div 200$ м/с. Полученная величина скорости струйного течения в процентном соотношении к скорости звука ( 6500 м/с) на предполагаемой глубине центра струйного течения в несколько километров под дном желоба составляет примерно $2 \div 4 \%$.

Найденная оценка значения скорости течения мантийной струи свидетельствует, что струи не являются столь же медленными, как течения мантии в крупных конвективных ячейках. Струйному течению, несомненно, препятствуют вязкие силы трения, которые для магматических расплавов значительны.

Достижение такой скорости движения мантии представляется возможным, и представленные простые выкладки показывают, что возникновение глубоководных океанических желобов может являться отражением существования мантийных струйных течений, расположенных под этими глубоководными желобами. Ширина океанического 
желоба связана с радиусом мантийного струйного течения. Описанный механизм не применяется здесь к какому-либо конкретному желобу и не отменяет действия других механизмов, таких как движение океанических и континентальных плит вблизи желобов.

\section{ОБСУЖДЕНИЕ РЕЗУЛЬТАТОВ}

Автору неизвестны экспериментальные данные об измерении скоростей распространения сейсмических сигналов для вертикального сейсмического разреза, взятого вдоль глубоководного желоба и, соответственно, вдоль струйного течения. Скорости струйного течения порядка $100 \div 200$ м/с должны сказываться на скоростях распространения сейсмических волн и, соответственно, на результатах измерений. Полученная оценка $100 \div 200$ м/с в процентном соотношении к скорости звука в верхней мантии есть $\approx 3 \%$. На вертикальном сейсмическом разрезе вдоль океанического желоба должна наблюдаться скоростная анизотропия порядка 3 \%

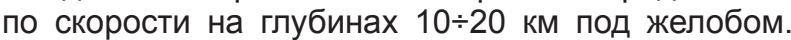
Другими словами, сейсмическое возмущение, распространяющееся вдоль оси струйного течения по направлению течения, должно преодолеть фриксированное расстояние быстрее, чем сейсмическое возмущение, распространяющееся вдоль оси струйного течения против направления течения. Это различие в скорости движения сейсмических возмущений можно зафиксировать экспериментально, построив вертикальный сейсмический разрез вдоль океанического желоба.

При получении вертикальных сейсмических разрезов не редкость получение скоростной анизотропии продольных скоростей сейсмических волн в пределах до 5 \%. Часто эта анизотропия скоростей сейсмических волн трактуется как течение материала, которое может приводить к преимущественной ориентации кристаллов слагающего мантию вещества. Анизотропия на сейсмических разрезах может быть прямо связана с мантийным течением на какой-либо глубине. Пользуясь крайне грубой полученной оценкой, можно предполагать, что наблюдаемая анизотропия продольных

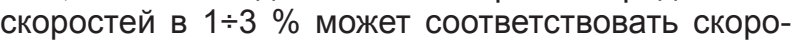
стям течения мантийных потоков в 100-200 м/с. В верхней мантии эти скорости могут оказаться достижимы. Современная техника позволяет проводить измерения с все возрастающей точностью, и знание направлений мантийных потоков и величин их скорости на глубинах 20-200 км может оказаться важным.

Отметим, что сила, возникающая над потоком мантийного струйного течения и могущая поддерживать равновесное (изостатическое) состояние желоба, направлена вертикально вниз. Следовательно, под действием этой силы должны формироваться одинаковые напряжения на обоих склонах океанического желоба. И в идеальных условиях, под действием одной только этой силы, должна наблюдаться одинаковая крутизна обоих склонов желоба. В реальных условиях сложное движение как континентальной, так и океанической плиты и различие их плотности могут формировать более сложное сечение склонов желоба.

Представленные рассуждения не проливают свет на причины возникновения рассматриваемых мантийных струйных течений. Действительно, если мантийные струи протекают неглубоко, то они могут проявляться в виде океанических желобов, но струйное течение, расположенное под глубоководным желобом, - лишь одна из возможных причин возникновения желоба.

Приведенные рассуждения и сделанные оценки необходимо дополнить указанием на достаточно долго действующую силу, под действием которой в мантии может сорормироваться струйное течение. Постоянно действующих сил известно три, и действуют они с момента возникновения планеты. Это силы гравитационного взаимодействия, центробежная сила и сила Кориолиса, действующая на движущийся элемент вещества в вращающейся системе координат. Гравитационные силы можно считать скомпенсированными нижележащими слоями мантии. Центробежные силы также скомпенсированы перераспределением массы гравитирующего вещества [8]. Сила Кориолиса, по своему определению, работы не совершает и не приводит в движение вещество, а только меняет направление уже существующего движения. А сила, фоормирующая и поддерживающая струйное течение мантии, совершает работу против сил вязкого трения, которые для магматических расплавов остаются значительными даже при относительно маленькой вязкости.

Казалось бы, поскольку исчерпан список обладающих необходимыми свойствами сил, выяснение причин существования струйных течений невозможно и рассмотренная простая модель не представляет собой даже теоретического интереса. Однако нужные нам для объяснения природы существования струйных течений силы существуют, и можно продемонстрировать их действие, хотя теоретические представления о них не развиты в полной мере. Чтобы показать, о чем идет речь, обратимся к аналогии.

Для выяснения причин движения вещества в струйном течении рассмотрим процессы в атмосфере. Атмосфера является еще одним геофизическим веществом, в котором действуют те же самые силы. Вместе с тем атмосфера гораздо лучше изучена при помощи методов непосредственного измерения давления, скоростей течения и температуры. По отношению к постоянно действующим силам, время действия которых составляет многие миллионы лет, и атмосфера и слой верхней мантии могут рассматриваться как жидкости, находящиеся в почти одинаковых условиях. Если одинаковые жидкости поставлены в одинаковые условия, то должны наблюдаться и похожие течения жидкости. На этом основании можно ожидать, что наблюдающиеся в атмосфере явления могут происходить и в верхней мантии.

Атмосфера отличается от литосферы по отношению к постоянно действующим силам двумя величинами: 1) значением вязкости, которая в ат- 
мосфере значительно ниже, чем вязкость магмы; и 2) в уравнении состояния для адиабатических процессов отличаются показатели степени (то есть различаются изменения плотности, связанные с изменениями давления).

В земной атмосфере, на высотах порядка 14-18 км, в каждый момент времени наблюдаются горизонтально направленные струйные течения воздуха [9], которые называются высокоуровневыми струйными течениями. Формирование этих течений связано с общей циркуляцией атмосферы. Высота поперечного сечения такого течения составляет $\approx 1 \div 5$ км и имеет форму эллипса, в горизонтальных направлениях сечение больше. Скорости этих струйных течений могут достигать в атмосфере 150 м/с или более, что составляет 50 \% или более в процентном отношении к скорости звука в воздухе на этих высотах. Высотные струйные течения зачастую огибают все меридианы земной поверхности на широте возникновения и замыкаются в циркулирующее постоянно течение. Струйное течение не является ффиксированным на широте своего возникновения и незначительно петляет с изменением меридиана, то поднимаясь севернее, то опускаясь южнее. Нет сомнений, что в атмосфере сила, поддерживающая существование высокоуровневых струйных течений, также совершает работу против сил вязкого трения.

Из измерений в атмосфере известно, что такие высотные струйные течения наблюдаются вблизи наиболее выраженных вертикальных градиентов температуры [9]. Такие градиенты температуры наблюдаются в верхней части областей соединения огромных конвективных ячеек, например, ячеек Хэдли и Ферреля, где и возникают сильные западные ветра в верхней тропосфрере, фрормирующие высотное струйное течение. Возможно, при достаточно больших вертикальных градиентах температуры возникает некоторый механизм, условно говоря, «неустойчивость», которая проявляется в возникновении горизонтального движения воздуха.

Можно предположить, что аналогичные струйные течения могут возникать в тех слоях верхней мантии, где велики вертикальные градиенты температуры. Действительно, глубокие океанические впадины наблюдаются вблизи вулканических областей, где можно ожидать изменений температуры по вертикали и латерали более существенных, чем в среднем по литосфрере.

Следовательно, можно ожидать возникновения струйных мантийных течений, которые, вероятно, тем мощнее, чем больше градиент температуры.

\title{
ЛИТЕРАТУРА
}

1. Богатиков О.А., Коваленко В.И., Шарков Е.В. Магматизм, тектоника, геодинамика Земли: связь во времени и пространстве. - М.: Наука, 2010. 606 c. ISBN 978-5-02-036923-8. 2. Рингвуд A.E. Состав и петрология мантии Земли. - M. Недра, 1981 2., 584 c.

3. Коллектив авторов. Спорные аспекты тектоники плит и возможные альтернативы. - М.: ИФЗ РАН, 2002. 236 с

4. Бартенев Г.М., Френкель С.Я. Физика полимеров / под ред д-ра ф. м. н. Ельяшевича А.М. - Л.: Химия, 1990. 432 с.

5. Жариков В.А. Основы физической геохимии. Серия Классический университетский учебник. Изд. 2, испр. и доп. - М.:

2005 2. 654 C.

6. Лебедев Е.Б., Хитаров Н.И. Физические свойства магматических расплавов. - М.: Наука, 1979, 200 с.

7. Магницкий В.А. Избранные труды: в 2 m. Т. 2. - М.: Наука, 2009. 374 c. ISBN 978-5-02-036660-2.

8. Ландау Л.Д., Лифиии Е.М. Теоретическая ффизика: учебное пособие.m. VI. Гидродинамика. - М.: Наука. Гл. Ред. Физ-мат Лum., 1988. 736 c. ISBN 5-02-013850-9.

9. Моханкумар К. Взаимодействие стратосферы и тропосореры. - М.: Физматлит, 2011. 452 с. ISBN 978-5-9221-1348-9.

\section{ON A PROBABLE DEEP-DWELLING OCEANIC TRENCH ORIGIN}

\author{
A.A. Radionoff
}

PhD, Southern Mathematical Institute - the Affiliate of Vladikavkaz Scientific Centre of Russian Academy of Sciences (SMI VSC RAS)

\begin{abstract}
A simple theoretical model of physical processes leading to the formation of deep-dwelling oceanic trenches is presented. Physical reasons of extensive warping in the oceanic crust are being discussed. In the case of physical mechanisms under consideration it assumes the existence of a mantle jet current flowing under a deep-sea trench, along its direction, which core is located at a depth of about a dozen kilometers below the ocean floor. The pressure above the moving mantle jet is less than the pressure above the surrounding stationary mantle. This difference in terms of pressure can lead to the warping of the ocean floor and is the vertical agency, leading to oceanic trenches formation. Possible causes, leading to mantle jet currents are discussed.
\end{abstract}

Keywords: Mathematical model, oceanic troughs, jet flow.

\section{REFERENCES}

1. Bogatikov O.A., Kovalenko V.I., Sharkov E.V. Magmatizm, tektonika, geodinamika Zemli: svyaz 'vo vremeni i prostranstve. - M.: Nauka, 2010. 606 s. ISBN 978-5-02-036923-8.

2. Ringvud A.E. Sostav i petrologiya mantii Zemli. - M.: Nedra, 1981 g., 584 s.

3. Kollektiv avtorov. Sporny`e aspekty` tektoniki plit i vozmozhny`e al'ternativy`. - M.: IFZ RAN, 2002. 236 s.

4. Bartenev G.M., Frenkel' S. Ya. Fizika polimerov / pod red. d-ra f. m. n. El'yashevicha A.M. - L.: Ximiya, 1990.432 s.

5. Zharikov V.A. Osnovy` fizicheskoj geoximii. Seriya Klassicheskij universitetskij uchebnik. Izd. 2, ispr. i dop. - M.: 2005

g. $654 \mathrm{~s}$.

6. Lebedev E.B., Xitarov N.I. Fizicheskie svojstva magmaticheskix rasplavov. - M.: Nauka, 1979, 200 s.

7. Magniczkij V.A. Izbranny`e trudy`: v 2 t. t. 2. - M.: Nauka, 2009. 374 s. ISBN 978-5-02-036660-2.

8. Landau L.D., Lifshicz E.M. Teoreticheskaya fizika: uchebnoe posobie.t. VI. Gidrodinamika. - M.: Nauka. GI. Red. Fiz-mat. Lit., 1988. 736 s. ISBN 5-02-013850-9.

9. Moxankumar K. Vzaimodejstvie stratosfery` i troposfery`. - M.: Fizmatlit, 2011. 452 s. ISBN 978-5-9221-1348-9. 